\title{
Relationship between burnout and career choice regret among Chinese neurology postgraduates
}

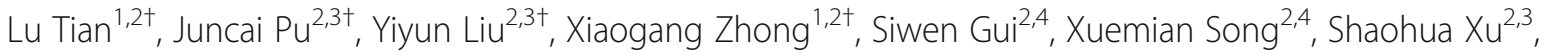
Xinyu Zhou ${ }^{2,3}$, Haiyang Wang ${ }^{2,4}$, Wei Zhou ${ }^{1,2}$, Jianjun Chen ${ }^{2,3}$ and Peng Xie ${\text { i, } 2,3,5^{*}}_{\text {(D) }}$

\begin{abstract}
Background: In China, the shortage of doctors leads to stressful clinical work and increasing turnover. Medical students undergoing postgraduate specialty training will be the country's medical workforce in the coming decades, but are also subject to high workloads and academic pressure. This may have significant implications for burnout and career choice regret. Despite the importance of burnout and career choice regret, the status and relationship of these aspects in Chinese neurology postgraduates are largely unexplored, and associated factors remain unknown.
\end{abstract}

Methods: This study investigated the prevalence of and factors influencing burnout and career choice regret among neurology postgraduates in China. We conducted a national cross-sectional study of Chinese neurology postgraduates. Data were collected using a self-administered questionnaire that covered demographic information, the Maslach Burnout Inventory, and additional item to assess career choice regret.

Results: Of 4902 neurology postgraduates, 2008 returned completed questionnaires (response rate 41\%). After excluding incomplete questionnaires, data for 1814 participants were analyzed. In total, 83.6\% of participants had experienced symptoms of burnout, and $46.6 \%$ reported career choice regret. Binary logistic regression analysis showed postgraduate entrance examination scores, marital status, and having children were associated with burnout (all $P<0.05$ ). Career choice regret was the strongest risk factor for burnout (odds ratio $[\mathrm{OR}]=3.17,95 \%$ confidence interval $[\mathrm{Cl}]$ 2.33-4.32). Multiple logistic regression showed postgraduates with shorter work or study hours per week $(\mathrm{OR}=0.64,95 \% \mathrm{Cl} 0.47-0.88)$ had a low risk for career choice regret, whereas married participants $(\mathrm{OR}=1.54,95 \% \mathrm{Cl} 1.07-2.20)$ had a high risk for career choice regret. No symptoms of burnout $(\mathrm{OR}=0.33$, $95 \% \mathrm{Cl} 0.24-0.45$ ) was also associated with a low risk for career choice regret.

Conclusions: Burnout symptoms and career choice regret are prevalent among neurology postgraduates in China. Career choice regret is an important predictor of burnout. Further research on reducing burnout and career choice regret among neurology postgraduates is needed.

Keywords: Neurology, Postgraduates, Burnout, Career choice regret, China

\footnotetext{
*Correspondence: xiepeng@cqmu.edu.cn

'Lu Tian, Juncai Pu, Yiyun Liu and Xiaogang Zhong contributed equally to this work.

${ }^{1}$ School of Public Health and Management, Chongqing Medical University,

Chongqing 400016, China

${ }^{2}$ Institute of Neuroscience, Chongqing Medical University, Chongqing

400016, China

Full list of author information is available at the end of the article
}

(c) The Author(s). 2019 Open Access This article is distributed under the terms of the Creative Commons Attribution 4.0 International License (http://creativecommons.org/licenses/by/4.0/), which permits unrestricted use, distribution, and reproduction in any medium, provided you give appropriate credit to the original author(s) and the source, provide a link to the Creative Commons license, and indicate if changes were made. The Creative Commons Public Domain Dedication waiver (http://creativecommons.org/publicdomain/zero/1.0/) applies to the data made available in this article, unless otherwise stated. 


\section{Background}

Burnout is a prolonged physical and mental response to chronic emotional and interpersonal job-related stressors [1]. It is characterized by emotional exhaustion, depersonalization, and low personal accomplishment, and has been an important research topic in psychology, organizational behavior, and human resource management for nearly 30 years [2, 3]. Individuals engaged in work that requires more personal sacrifice, particularly medical workers, are at high risk for burnout [4]. The high prevalence of burnout among physicians has become a global issue. For example, burnout was reported by $54.4 \%$ of physicians in the US [5], $50 \%$ of physicians in Brazil [6], 72\% of psychiatrists in Japan [7], and $60.6 \%$ of physicians in China [8]. Moreover, burnout may lead to poor patient care and reduced job satisfaction [9].

Medical postgraduates or interns often work long hours and have heavy workloads, which may increase the risk for burnout and career choice regret. The incidence of burnout was $20 \%$ among medical interns in Mexico [10], 52.8-76\% in US medical students [11, 12], and $45.2 \%$ in US resident physicians [13]. In China, medical postgraduates are resident physicians or junior researchers who receive standardized training for 3 years $[14,15]$. The incidence of burnout in this population is reported to range from $38.4-51.3 \%$ [16, 17]. Burnout is also associated with career choice regret, unprofessional conduct, and even suicidal ideation [13, 18]. Burnout was found to be the single greatest predictor of career choice regret among US resident physicians and surgeons [19]. Other studies also showed that burnout and career choice regret were common among doctors and medical postgraduates. For example, previous studies reported $58.1 \%$ of neurologists regretted becoming a doctor [20] and $62 \%$ of medical students regretted choosing to study medicine [21]. However, factors associated with burnout and career choice regret vary among different populations. Individual characteristics, organizational factors, and sub-specialty choice may be determinants of burnout and career choice regret among medical students $[13,22]$.

Previous surveys suggest that neurology is a specialty with high levels of job-related burnout and low levels of satisfaction $[23,24]$. The workforce demand for neurologists has increased sharply in recent years with population aging. A survey in the US estimated the shortfall of neurologists was approximately $11 \%$ in 2012, but would increase to $19 \%$ by 2025 [25]. Career satisfaction among neurologists has also declined in recent years [26], which suggests employment motivation among medical postgraduates may be important in addressing the shortage of doctors. However, more research is needed to identify determinants of burnout and career choice regret for Chinese neurology postgraduates. Alleviating the symptoms of burnout and reducing career choice regret to maintain neurology postgraduates' original intention of studying medicine may decrease the turnover rate and ensure the future supply and quality of neurologists.

Despite the widely acknowledged importance of burnout and career choice regret [13, 27], the status and relationship of these two aspects among Chinese neurology postgraduates are largely unexplored. In this national study, we examined the status of and factors associated with burnout and career choice regret among Chinese neurology postgraduates. Based on our findings, we proposed some suggestions that may be helpful to inform employment measures.

\section{Methods}

Study designs, setting, and participants

This survey was conducted by the China Neurologist Association from September 2014 to March 2015. The study design was adapted from our previous study [20]. In brief, with the assistance of local neurologist associations, neurology postgraduates were invited to complete a self-administered questionnaire. Data collection and analysis were performed by independent researchers blinded to the experiment design.

\section{Standard protocol approval and participant consent}

The cover letter for the questionnaire introduced the purpose of the survey, which was to explore the status of and factors potentially associated with burnout and career choice regret. The cover letter also stated that participation was voluntary and anonymous, and personal privacy would not be violated in the study processes. Consent was assumed for any participant who returned a completed survey. Ethics approval was granted by the Ethics Committee of Chongqing Medical University.

\section{Survey questionnaire}

The survey questionnaire contained four parts. Part 1 covered demographic variables, including gender, academic year, age, degree type, postgraduate entrance examination score, hours worked or studied per week, hours slept per day, marital status, whether the respondent had children, and work type (part-or full-time). Part 2 comprised the Maslach Burnout Inventory [28]. This instrument measures three domains of burnout (emotional exhaustion, depersonalization, and personal accomplishment) using a seven-point Likert-type scale (range 0-6). We considered participants to have high levels of burnout if they scored more than 27 points for emotional exhaustion or more than 10 points for depersonalization [20, 29]. Part 3 included a question investigating career choice regret: "If you could go back, 
would you choose to become a doctor again?" Response options were 'no,' 'neutral' and 'yes'; responses of 'no' indicated career choice regret. This question was used to assess career choice regret in previous studies [13, 19]. Part 4 included three additional questions: "Will you choose to become a doctor after graduation?", "What do you think of the current medical environment?" and "Have you ever considered dropping out?"

\section{Statistical analysis}

All statistical analyses were performed with SPSS version 21.0 (IBM Corp, Armonk, NY, USA). Associations between variables were evaluated using univariate analysis with a chi-square test for categorical variables. Binary logistic regression analysis was used to verify the factors affecting burnout. We fitted three logistic regression models. Model 1 was adjusted for all demographic variables, Model 2 for career choice regret, and Model 3 for demographic variables and career choice regret. Multicollinearity analysis was used to test collinearity among variables when the tolerance was $\leq 0.1$ or the variance inflation factor was $\geq 10$. Three methods (enter model, backward elimination method, and forward elimination method) were used to select significant independent variables in the logistic models. Multiple logistic regression analysis was used to identify factors potentially associated with career choice regret. For the dependent variable (career choice regret), the category 'without career choice regret' was set as the reference category. Demographic variables and burnout were independent variables. A $P$-value below 0.05 was considered statistically significant.

\section{Results}

In March 2015, 4902 questionnaires were distributed, and 2008 collected from 249 hospitals (response rate 41.0\%). We excluded 194 invalid questionnaires because of missing data for the Maslach Burnout Inventory, leaving 1814 questionnaires for analysis.

\section{Demographic characteristics}

Table 1 shows the characteristics of the participating neurology postgraduates. Overall, $67.1 \%$ of participants were female, $68.5 \%$ were in clinical practice with the remainder in academic positions, and $85.7 \%$ had a master's degree. Around half of the participants reported a family income less than 5000 RMB per month, and 40.2\% worked more than $55 \mathrm{~h}$ per week. Most participants were unmarried $(83.1 \%)$ and $67.5 \%$ did not have children.

\section{Prevalence and univariate analysis of burnout and career} choice regret

Table 2 summarizes the prevalence of burnout and career choice regret. In general, $83.6 \%$ of participants had symptoms of burnout (high emotional exhaustion or depersonalization scores). In terms of career choice regret, $46.6 \%$ said that they would not choose to be doctor again, and $18.1 \%$ were unsure. Half of the participants with symptoms of burnout had career choice regret (Fig. 1). In addition, $7.3 \%$ of participants said they did not want to be a doctor when they graduated and $17.6 \%$ had thought about dropping out at least once. Only $2.9 \%$ thought that the current medical environment was good. In Table 1, burnout was associated with postgraduate entrance examination score, hours worked or studied per week, marital status, and having children (all $P<0.05$ ). In the univariate analysis (Table 3), career choice regret was associated with academic year, degree type, family income, hours slept per day, and marital status (all $P<0.05$ ).

\section{Factors associated with burnout and career choice regret in the multivariate analysis}

The multicollinearity analysis indicated there was no collinearity for burnout (Additional file 1). Table 4 summarizes the factors associated with burnout and career choice regret. Model 1, in which demographic variables were entered, showed factors independently associated with burnout were gender, postgraduate entrance examination score, hours worked or studied per week, marital status, and having children (all $P<0.05$ ). Women were at higher risk for burnout than men (odds ratio $[\mathrm{OR}]=$ 0.74, 95\% confidence interval [CI] 0.56-0.99). Married postgraduates $(\mathrm{OR}=0.56,95 \% \mathrm{CI} 0.39-0.80)$ and those without children $(\mathrm{OR}=0.55,95 \% \mathrm{CI} 0.40-0.77)$ were less likely to show symptoms of burnout. Model 2 (including career choice regret) showed career choice regret was independently associated with burnout $(P<0.05)$. In Model 3 (both demographic variables and career choice regret), being married and without children were protective factors. Career choice regret was the strongest risk factor for burnout (OR $=3.17,95 \%$ CI 2.33-4.32).

Multiple logistic regression analysis showed postgraduates with shorter hours worked or studied per week (OR $=0.64,95 \%$ CI $0.47-0.88)$ had a low risk for career choice regret, whereas postgraduates who were married $(\mathrm{OR}=1.54,95 \% \mathrm{CI} 1.07-2.20)$ had a high risk. Being without symptoms of burnout (OR $=0.33$, 95\% CI $0.24-$ $0.45)$ was also associated with a low risk for career choice regret (Table 5).

\section{Discussion}

This nationwide study used a questionnaire survey to assess burnout and career choice regret in Chinese neurology postgraduates. We found a high prevalence of burnout and career choice regret among participants, with burnout being closely related to career choice 
Table 1 Demographic characteristics associated with burnout

\begin{tabular}{|c|c|c|c|c|c|}
\hline \multirow[t]{2}{*}{ Characteristics } & \multirow[t]{2}{*}{$\mathrm{N}$} & \multirow[t]{2}{*}{$\%$} & \multicolumn{2}{|l|}{ Burnout } & \multirow[t]{2}{*}{$P$} \\
\hline & & & Without & With & \\
\hline \multicolumn{6}{|l|}{ Gender } \\
\hline Male & 593 & 32.7 & $112(37.6)$ & $481(31.8)$ & \multirow[t]{2}{*}{0.05} \\
\hline Female & 1218 & 67.1 & $186(62.4)$ & $1032(68.2)$ & \\
\hline \multicolumn{6}{|l|}{ Academic year } \\
\hline First-year, master's degree & 391 & 21.6 & $74(25.8)$ & $317(21.3)$ & \multirow[t]{6}{*}{0.10} \\
\hline Second-year, master's degree & 554 & 30.5 & $77(26.8)$ & $477(32.1)$ & \\
\hline Third-year, master's degree & 609 & 33.6 & $109(38.0)$ & $500(33.6)$ & \\
\hline First-year, doctor's degree & 79 & 4.4 & $10(3.5)$ & $69(4.6)$ & \\
\hline Second-year, doctor's degree & 73 & 4.0 & $11(3.8)$ & $62(4.2)$ & \\
\hline Third-year, doctor's degree & 68 & 3.7 & $6(2.1)$ & $62(4.2)$ & \\
\hline \multicolumn{6}{|l|}{ Degree type } \\
\hline Clinical practice & 1243 & 68.5 & $209(71.3)$ & $1034(69.8)$ & \multirow[t]{2}{*}{0.59} \\
\hline Academic practice & 532 & 29.3 & $84(28.7)$ & $448(30.2)$ & \\
\hline \multicolumn{6}{|l|}{ Family income (yuan per month) } \\
\hline$<5000$ & 901 & 49.7 & $154(51.9)$ & 747 (49.6) & \multirow[t]{4}{*}{0.88} \\
\hline $5000-10,000$ & 603 & 33.2 & $95(32.0)$ & $508(33.7)$ & \\
\hline $10,000-15,000$ & 176 & 9.7 & $27(9.1)$ & $149(9.9)$ & \\
\hline$>15,000$ & 124 & 6.8 & $21(7.1)$ & $103(6.8)$ & \\
\hline \multicolumn{6}{|c|}{ Scores of postgraduate entrance examination } \\
\hline$<300$ & 221 & 12.2 & $55(21.5)$ & $166(13.0)$ & \multirow[t]{4}{*}{$<0.01$} \\
\hline $300-330$ & 698 & 38.5 & $93(36.3)$ & $605(47.4)$ & \\
\hline $330-360$ & 422 & 23.3 & $75(29.3)$ & $347(27.2)$ & \\
\hline$>360$ & 192 & 10.6 & $33(12.9)$ & $159(12.5)$ & \\
\hline \multicolumn{6}{|c|}{ Hours worked or studied per week (h) } \\
\hline$<35$ & 132 & 7.3 & $28(9.5)$ & $104(6.9)$ & \multirow[t]{4}{*}{0.02} \\
\hline $35-45$ & 428 & 23.6 & $75(25.4)$ & $353(23.4)$ & \\
\hline $45-55$ & 512 & 28.2 & $96(32.5)$ & $416(27.6)$ & \\
\hline$>55$ & 732 & 40.4 & $96(32.5)$ & $636(42.1)$ & \\
\hline \multicolumn{6}{|l|}{ Hours slept per day (h) } \\
\hline$<6$ & 224 & 12.3 & $33(11.1)$ & $191(12.6)$ & \multirow[t]{3}{*}{0.25} \\
\hline $6-8$ & 1462 & 80.6 & $238(79.9)$ & $1224(80.8)$ & \\
\hline $8-10$ & 126 & 6.9 & $27(9.1)$ & $99(6.5)$ & \\
\hline \multicolumn{6}{|l|}{ Marital status } \\
\hline Married & 302 & 16.6 & $65(21.8)$ & $237(15.7)$ & \multirow[t]{2}{*}{0.01} \\
\hline Unmarried & 1507 & 83.1 & $233(78.2)$ & $1274(84.3)$ & \\
\hline \multicolumn{6}{|l|}{ Whether have children } \\
\hline Without & 1224 & 67.5 & $222(74.5)$ & $1002(66.2)$ & \multirow[t]{2}{*}{0.01} \\
\hline Have & 588 & 32.4 & $76(25.5)$ & $512(33.8)$ & \\
\hline \multicolumn{6}{|l|}{ Whether to work part-time once } \\
\hline Without & 1116 & 61.5 & $187(63.6)$ & $929(61.6)$ & \multirow[t]{2}{*}{0.51} \\
\hline Have & 687 & 37.9 & $107(36.4)$ & $580(38.4)$ & \\
\hline
\end{tabular}


Table 2 Prevalence of burnout, career choice regret and responses to 3 other questions

\begin{tabular}{ll}
\hline Characteristics & N (\%) \\
\hline Burnout & $1516(83.6 \%)$ \\
With & $298(16.4 \%)$ \\
Without & \\
Career choice regret & $845(46.6 \%)$ \\
With & $329(18.1 \%)$ \\
Neutral & $637(35.1 \%)$ \\
Without & \\
Wished to be a doctor when graduate & $132(7.3 \%)$ \\
No & $360(19.8 \%)$ \\
Neutral & $1314(72.4 \%)$ \\
Yes & \\
View on current medical environment & $52(2.9 \%)$ \\
Good & $711(39.2 \%)$ \\
Neutral & $1043(57.5 \%)$ \\
Poor & \\
Considered dropping out once & $319(17.6 \%)$ \\
Yes & $1477(81.4 \%)$ \\
No &
\end{tabular}

regret. To our knowledge, this study is the first to examine this issue in this population.

\section{Prevalence and predictors of burnout}

The prevalence of burnout among Chinese neurology postgraduates was $83.6 \%$, which was higher than reported for other professions worldwide. For example, most previous studies suggested that Chinese medical postgraduates showed moderate levels of burnout [22]. For other clinical postgraduates in different countries, reported burnout rates were $63 \%$ for internal medicine,
$60 \%$ for ophthalmology, and $40 \%$ for general surgery [30]. The incidence of burnout among US medical students was $76 \%$ [11]. The high prevalence of burnout in our sample may be attributable to the complexity of diagnosis and treatment for neurological diseases and the high pressure and low career satisfaction associated with this specialty $[20,31]$. Our study showed that working long hours was a major risk factor for burnout, which was consistent with previous findings [32]. However, a study involving Dutch residents showed that although their working hours were restricted to $48 \mathrm{~h}$ per week, many doctors still suffered from burnout, which suggests that factors other than working hours may also be important [33].

Model 3 showed career choice regret was the most important factor influencing burnout. A study in Europe found that burnout tended to affect feelings and attitudes towards work, rather than actual working time [34]. We found that postgraduates with burnout had a high risk for career choice regret, which was consistent with previous studies [13, 18, 19]. Previous studies demonstrated that turnover among doctors can be significantly reduced by intervening in burnout [3]. Therefore, more attention should be paid to career choice regret among postgraduates to reduce future losses of neurologists.

\section{Prevalence and predictors of career choice regret}

Career choice regret is an attitude and belief that individuals have about their work. It reflects internal professional values and motivation, both of which determine career choices [35]. In this survey, nearly half of the participating postgraduates would not choose to be a doctor again, indicating that many neurology postgraduates were dissatisfied with their career choice. In addition, about one-quarter of participants had thought about

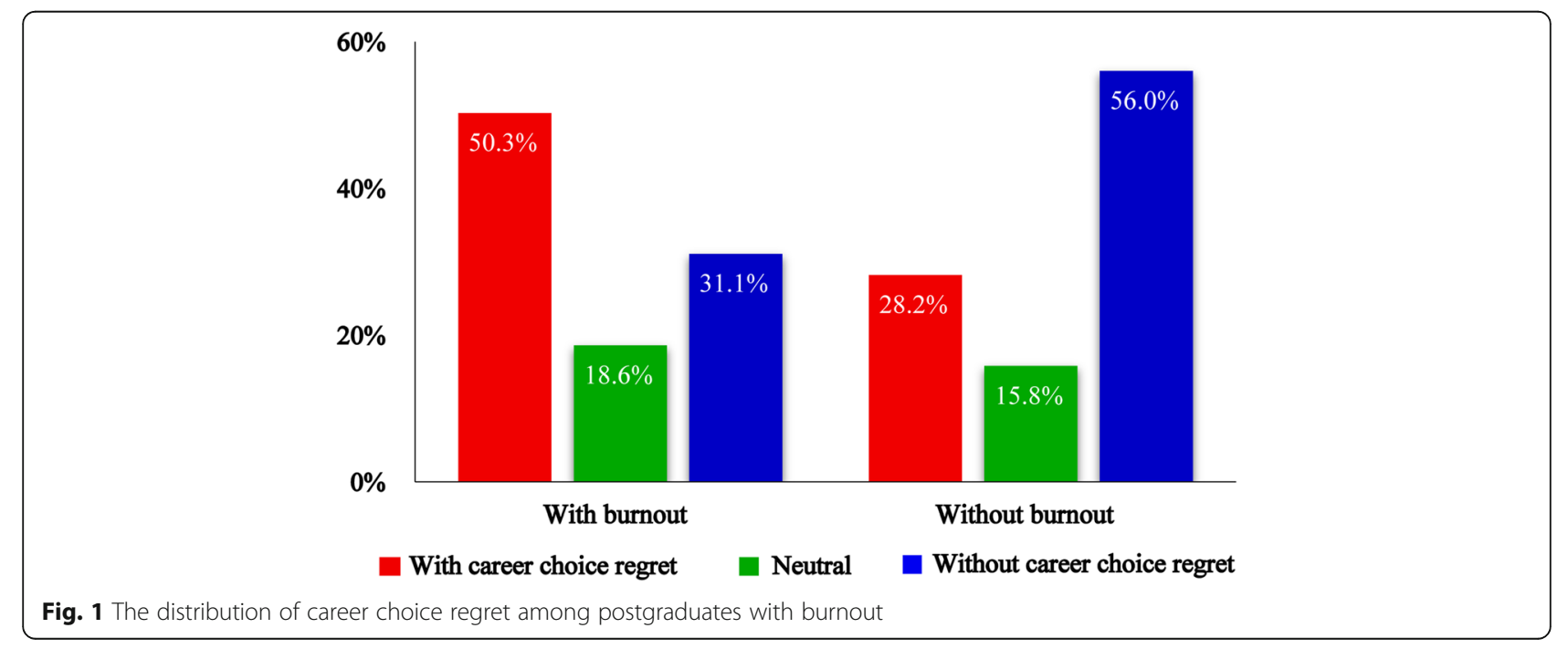


Table 3 Demographic characteristics associated with career choice regret

\begin{tabular}{|c|c|c|c|c|}
\hline \multirow[t]{2}{*}{ Characteristics } & \multicolumn{4}{|c|}{ Career choice regret } \\
\hline & With & Neutral & Without & $P$ \\
\hline \multicolumn{5}{|l|}{ Gender } \\
\hline Male & $266(44.9 \%)$ & $112(18.9 \%)$ & $215(36.3 \%)$ & \multirow[t]{2}{*}{0.57} \\
\hline Female & $577(47.5 \%)$ & $217(17.9 \%)$ & $421(34.7 \%)$ & \\
\hline \multicolumn{5}{|l|}{ Academic year } \\
\hline First-year, master's degree & $167(42.7 \%)$ & $63(16.1 \%)$ & $161(41.2 \%)$ & \multirow[t]{6}{*}{$<0.01$} \\
\hline Second-year, master's degree & $251(45.5 \%)$ & $120(21.7 \%)$ & $181(32.8 \%)$ & \\
\hline Third-year, master's degree & $295(48.5 \%)$ & $103(16.9 \%)$ & $210(34.5 \%)$ & \\
\hline First-year, doctor's degree & $29(36.7 \%)$ & $21(26.6 \%)$ & $29(36.7 \%)$ & \\
\hline Second-year, doctor's degree & $41(56.2 \%)$ & $12(16.4 \%)$ & $20(27.4 \%)$ & \\
\hline Third-year, doctor's degree & $40(58.8 \%)$ & $6(8.8 \%)$ & $22(32.4 \%)$ & \\
\hline \multicolumn{5}{|l|}{ Degree type } \\
\hline Clinical practice & $600(48.4 \%)$ & $210(16.9 \%)$ & $430(34.7 \%)$ & \multirow[t]{2}{*}{0.03} \\
\hline Academic practice & $225(42.3 \%)$ & $114(21.4 \%)$ & $193(36.3 \%)$ & \\
\hline \multicolumn{5}{|l|}{ Family income (yuan per month) } \\
\hline$<5000$ & $435(48.4 \%)$ & $133(14.8 \%)$ & $330(36.7 \%)$ & \multirow[t]{4}{*}{$<0.01$} \\
\hline $5000-10,000$ & $275(45.6 \%)$ & $101(16.7 \%)$ & $227(37.6 \%)$ & \\
\hline $10,000-15,000$ & $76(43.2 \%)$ & $51(29.0 \%)$ & $49(27.8 \%)$ & \\
\hline$>15,000$ & $51(41.1 \%)$ & $43(34.7 \%)$ & $30(24.2 \%)$ & \\
\hline \multicolumn{5}{|c|}{ Scores of postgraduate entrance examination } \\
\hline$<300$ & 99 (45.2\%) & $34(15.5 \%)$ & $86(39.3 \%)$ & \multirow[t]{4}{*}{0.51} \\
\hline $300-330$ & $335(48.1 \%)$ & $126(18.1 \%)$ & $236(33.9 \%)$ & \\
\hline $330-360$ & $185(43.8 \%)$ & 88 (20.9\%) & $149(35.3 \%)$ & \\
\hline$>360$ & $86(44.8 \%)$ & $34(17.7 \%)$ & $72(37.5 \%)$ & \\
\hline \multicolumn{5}{|c|}{ Hours worked or studied per week (h) } \\
\hline$<35$ & $62(47.0 \%)$ & $18(13.6 \%)$ & $52(39.4 \%)$ & \multirow[t]{4}{*}{0.14} \\
\hline $35-45$ & $193(45.2 \%)$ & $70(16.4 \%)$ & $164(38.4 \%)$ & \\
\hline $45-55$ & $225(26.8 \%)$ & $102(31.3 \%)$ & $185(29.2 \%)$ & \\
\hline$>55$ & $361(49.5 \%)$ & $136(18.6 \%)$ & $233(31.9 \%)$ & \\
\hline \multicolumn{5}{|l|}{ Hours slept per day (h) } \\
\hline$<6$ & $122(54.7 \%)$ & $44(19.7 \%)$ & $57(25.6 \%)$ & \multirow[t]{3}{*}{$<0.01$} \\
\hline $6-8$ & $671(46.0 \%)$ & $253(17.3 \%)$ & $536(36.7 \%)$ & \\
\hline $8-10$ & $50(39.7 \%)$ & $32(25.4 \%)$ & $44(34.9 \%)$ & \\
\hline \multicolumn{5}{|l|}{ Marital status } \\
\hline Married & $167(55.3 \%)$ & 46 (15.2\%) & 89 (29.5\%) & \multirow[t]{2}{*}{$<0.01$} \\
\hline Unmarried & $676(44.9 \%)$ & $282(18.8 \%)$ & $546(36.3 \%)$ & \\
\hline \multicolumn{5}{|l|}{ Whether have children } \\
\hline Without & $551(45.1 \%)$ & $221(18.1 \%)$ & $449(36.8 \%)$ & \multirow[t]{2}{*}{0.11} \\
\hline Have & $293(49.8 \%)$ & $107(18.2 \%)$ & $188(32.0 \%)$ & \\
\hline \multicolumn{5}{|l|}{ Whether to work part-time once } \\
\hline Without & $498(44.7 \%)$ & $214(19.2 \%)$ & $403(36.1 \%)$ & \multirow[t]{2}{*}{0.06} \\
\hline Have & $344(50.2 \%)$ & $112(16.4 \%)$ & $229(33.4 \%)$ & \\
\hline
\end{tabular}


Table 4 Burnout with associated factors ${ }^{\mathrm{a}}$

\begin{tabular}{|c|c|c|c|c|c|c|}
\hline \multirow[t]{2}{*}{ Characteristics } & \multicolumn{2}{|l|}{ Model $1^{\mathrm{b}}$} & \multicolumn{2}{|l|}{ Model $2^{c}$} & \multicolumn{2}{|l|}{ Model $3^{d}$} \\
\hline & OR $(95 \% \mathrm{Cl})$ & P & OR $(95 \% \mathrm{Cl})$ & P & OR $(95 \% \mathrm{Cl})$ & $P$ \\
\hline \multicolumn{7}{|l|}{ Gender } \\
\hline Male & $0.74(0.56-0.99)$ & 0.04 & & & & \\
\hline Female & 1 (Reference) & & & & 1 (Reference) & \\
\hline \multicolumn{7}{|c|}{ Scores of postgraduate entrance examination } \\
\hline$<300$ & $0.81(0.49-1.36)$ & 0.43 & & & $0.68(0.41-1.12)$ & 0.13 \\
\hline $300-330$ & $1.60(1.02-2.51)$ & 0.04 & & & $1.40(0.90-2.19)$ & 0.14 \\
\hline $330-360$ & $1.09(0.69-1.74)$ & 0.71 & & & $0.98(0.61-1.55)$ & 0.92 \\
\hline$>360$ & 1 (Reference) & & & & 1 (Reference) & \\
\hline \multicolumn{7}{|c|}{ Hours worked or studied per week (h) } \\
\hline$<35$ & $0.47(0.28-0.78)$ & $<0.01$ & & & & \\
\hline $35-45$ & $0.60(0.41-0.86)$ & $<0.01$ & & & & \\
\hline $45-55$ & $0.58(0.41-0.82)$ & $<0.01$ & & & & \\
\hline$>55$ & 1 (Reference) & & & & & \\
\hline \multicolumn{7}{|l|}{ Marital status } \\
\hline Married & $0.56(0.39-0.80)$ & $<0.01$ & & & $0.50(0.35-0.71)$ & $<0.01$ \\
\hline Unmarried & 1 (Reference) & & & & 1 (Reference) & \\
\hline \multicolumn{7}{|c|}{ Whether have children } \\
\hline Without & $0.55(0.40-0.77)$ & $<0.01$ & & & $0.58(0.42-0.82)$ & $<0.01$ \\
\hline Have & 1 (Reference) & & & & 1 (Reference) & \\
\hline \multicolumn{7}{|c|}{ Career choice regret } \\
\hline With & & & $3.22(2.42-4.29)$ & $<0.01$ & $3.17(2.33-4.32)$ & $<0.01$ \\
\hline Neutral & & & $2.13(1.49-3.04)$ & $<0.01$ & $2.97(1.95-4.54)$ & $<0.01$ \\
\hline Without & & & 1 (Reference) & & 1 (Reference) & \\
\hline
\end{tabular}

Abbreviations: $\mathrm{Cl}=$ confidence interval, $O R=$ odds ratio

${ }^{a} \mathrm{OR}<1$ indicates that it is a preventive factor of burnout, where as $\mathrm{OR}>1$ indicates that it is a risk factor of burnout

${ }^{\mathrm{b}}$ In model 1, demographic characteristics was independent variables

'In model 2, career choice regret was the independent variables

${ }^{\mathrm{d}}$ In model 3, both demographic variables and career choice regret were independent variables

dropping out at least once. A previous survey in the US found that approximately $11 \%$ of students have serious thoughts of dropping out of medical school each year [36]. The difference between that study and ours may be related to the medical environment. A previous study suggested that a poor medical environment affected medical students' professional identity and had a significant impact on their career choices, which were particularly affected by long working hours, pressure from medical disputes, and violence against medical workers [35]. It can be speculated that a poor medical environment may increase the risk for career choice regret.

We found that sleep deprivation and family factors were important elements in career choice regret. A previous study also found that chronic sleep deprivation caused depression and anxiety, which affected attitudes and efficiency at work [37]. Family factors included family income, marital status, and whether the participant had children. Postgraduates with a low monthly family income were more likely to plan to become doctors, which may because doctors are well-paid comparing with other careers. Those who were married had a high risk for career choice regret, possibly because their heavy clinical workload may lead to conflict between work and family life, and strained relationships with their spouse or children. A study [23] suggested that career choice regret among neurology residents was influenced by work-family compatibility, which was consistent with our findings.

\section{Further measures}

Preventing burnout among medical students and reducing career choice regret are important to ensure there are enough neurologists to meet global demand. These tasks call for active cooperation from the government, hospitals, and medical students. First, the government 
Table 5 Career choice regret with associated factor

\begin{tabular}{|c|c|c|c|}
\hline Career choice regret ${ }^{a}$ & Variables & OR $(95 \% \mathrm{Cl})$ & $P$ value \\
\hline \multirow[t]{18}{*}{ Neutral versus without career choice regret } & \multicolumn{3}{|l|}{ Academic year } \\
\hline & First-year, master's degree & $1.91(0.64-5.69)$ & 0.25 \\
\hline & Second-year, master's degree & $3.19(1.10-9.26)$ & 0.03 \\
\hline & Third-year, master's degree & $2.45(0.85-7.07)$ & 0.10 \\
\hline & First-year, doctor's degree & $2.66(0.76-9.24)$ & 0.13 \\
\hline & Second-year, doctor's degree & $1.69(0.43-6.61)$ & 0.45 \\
\hline & Third-year, doctor's degree & 1 (Reference) & \\
\hline & \multicolumn{3}{|c|}{ Hours worked or studied per week (h) } \\
\hline & $<35$ & $0.84(0.52-1.35)$ & 0.47 \\
\hline & $35-45$ & $0.64(0.47-0.88)$ & 0.01 \\
\hline & $45-55$ & $0.66(0.49-0.90)$ & 0.01 \\
\hline & $>55$ & 1 (Reference) & \\
\hline & \multicolumn{3}{|l|}{ Marital status } \\
\hline & Married & $1.24(1.07-2.20)$ & 0.02 \\
\hline & Unmarried & 1 (Reference) & \\
\hline & \multicolumn{3}{|l|}{ Burnout } \\
\hline & Without & $0.33(0.24-0.45)$ & $<0.01$ \\
\hline & With & 1 (Reference) & \\
\hline \multirow[t]{11}{*}{ With career choice regret versus without career choice regret } & \multicolumn{3}{|c|}{ Hours worked or studied per week (h) } \\
\hline & $<35$ & $0.84(0.52-1.35)$ & 0.47 \\
\hline & $35-45$ & $0.64(0.47-0.88)$ & $<0.01$ \\
\hline & $45-55$ & $0.66(0.49-0.90)$ & $<0.01$ \\
\hline & $>55$ & 1 (Reference) & \\
\hline & \multicolumn{3}{|l|}{ Marital status } \\
\hline & Married & $1.54(1.07-2.20)$ & 0.02 \\
\hline & Unmarried & 1 (Reference) & \\
\hline & \multicolumn{3}{|l|}{ Burnout } \\
\hline & Without & $0.33(0.24-0.45)$ & $<0.01$ \\
\hline & With & 1 (Reference) & \\
\hline
\end{tabular}

Abbreviations: $\mathrm{Cl}=$ confidence interval, $O R=$ odds ratio

${ }^{a} \mathrm{OR}<1$ indicates that it is a preventive factor of career choice regret, where as $\mathrm{OR}>1$ indicates that it is a risk factor of career choice regret

Note: The reference category is: without career choice regret

could reform the medical system and improve the medical environment, which may improve postgraduates' career choices and enhance the social and economic status of doctors/postgraduates. Second, hospitals could facilitate the construction of healthy working environments (both physically and mentally) through improving working conditions, rationally allocating workers, and setting up career development planning for staff. Hospitals could also ensure staff has sufficient rest time, and pay attention to any psychological problems among postgraduates. Third, it is important for postgraduates to understand burnout correctly, improve their physical and psychological status, and pay attention to the balance of work and rest.

\section{Limitations}

This study had a number of limitations. First, the survey did not use random sampling methods, which might have resulted in selection and response bias. However, the findings of this study may have some generalizability given the large and diverse sample. Second, only limited information was collected on demographic characteristics and other influencing factors, and burnout and career choice regret may be affected by other confounding variables. Third, the survey was cross-sectional, and we could not examine dynamic changes in burnout factors, which may be influenced by geography, professional factors, the local practice environment, and practice types. Further studies with more rigorous designs are needed to confirm these findings. 


\section{Conclusion}

Overall, symptoms of burnout and career choice regret are prevalent among Chinese neurology postgraduates. Career choice regret is the strongest predictor of burnout in this population. Our results provide a high-level overview to support interventions to prevent burnout and improve career choice regret. Active measures from the government, hospitals, and postgraduates are needed to change the current situation.

\section{Additional file}

Additional file 1: The initial and final logistic models of binary logistic regression analysis of burnout. (XLS $41 \mathrm{~kb}$ )

\section{Acknowledgments}

Not applicable.

\section{Funding}

The author(s) disclosed receipt of the following financial support for the research, authorship and/or publication of this article: This study was funded by the National key research and development plan of Project Grant 2017YFA0505700. And Chongqing Postgraduate Innovation Project (Grant No. CYS17173).

\section{Availability of data and materials}

The datasets used and/or analyzed during the current study are available from the corresponding author on reasonable request.

\section{Author's contributions}

$L T, J C P, Y Y L, X G Z, P X$ contributed to the conception and design of the study, LT, SWG, XMS, WZ collected the information, SHX, XYZ, HYW, JJC performed the statistical analysis, $L T, Y Y L, X G Z$ wrote the first draft of the manuscript, $J C P, P X$ revised the final version of the manuscript. All authors read and approved the final manuscript.

\section{Ethics approval and consent to participate}

Ethics approval was granted by the ethics committee of Chongqing Medical University. Consent to participate was obtained from the participants.

\section{Consent for publication}

Permissions were also obtained from the participants to publish their data anonymously.

\section{Competing interests}

The author(s) declared no potential conflicts of interest with respect to the research, authorship, and/or publication of this article.

\section{Publisher's Note}

Springer Nature remains neutral with regard to jurisdictional claims in published maps and institutional affiliations.

\footnotetext{
Author details

'School of Public Health and Management, Chongqing Medical University, Chongqing 400016, China. ${ }^{2}$ Institute of Neuroscience, Chongqing Medical University, Chongqing 400016, China. ${ }^{3}$ Department of Neurology, The First Affiliated Hospital of Chongqing Medical University, Chongqing 400016, China. ${ }^{4}$ College of Biomedical Engineering, Chongqing Medical University, Chongqing 400016, China. ${ }^{5}$ China Neurologist Association of Chinese Medical Doctor Association, Beijing 100010, China.
}

Received: 16 January 2019 Accepted: 9 May 2019

Published online: 22 May 2019

\section{References}

1. Maslach C, Jackson SE, Leiter MP. Maslach burnout inventory manual. 3rd ed. Consulting Psychologists Press; 1997.

2. Bianchi R, Mayor E, Schonfeld IS, Laurent E. Burnout and depressive symptoms are not primarily linked to perceived organizational problems. Psychol Health Med. 2018;23(9):1094-105.

3. Panagioti M, Panagopoulou E, Bower P, Lewith G, Kontopantelis E, Chewgraham $C$, et al. Controlled interventions to reduce burnout in physicians: a systematic review and meta-analysis. JAMA Intern Med. 2017:177(2):195-205.

4. Yao SM, Yu HM, Ai YM, Song PP, Meng SY, Li W. Job-related burnout and the relationship to quality of life among Chinese medical college staff. Arch Environ Occup Health. 2015;70(1):27-34.

5. Shanafelt TD, Hasan O, Dyrbye LN, Sinsky C, Satele D, Sloan J, et al. Changes in burnout and satisfaction with work-life balance in physicians and the general us working population between 2011 and 2014. Mayo Clin Proc 2015:90(12):1600-13.

6. Garcia TT, Garcia PCR, Molon ME, Piva JP, Tasker RC, Branco RG, et al. Prevalence of burnout in pediatric intensivists: an observational comparison with general pediatricians. Pediatr Crit Care Med. 2014;15(8):e347-53.

7. Umene-Nakano W, Kato TA, Kikuchi S, Tateno M, Fujisawa D, Hoshuyama T, et al. Nationwide survey of work environment, work-life balance and burnout among psychiatrists in Japan. PLoS One. 2013;8(2):e55189.

8. Wang Z, Xie Z, Dai J, Zhang L, Huang Y, Chen B. Physician burnout and its associated factors: a cross-sectional study in Shanghai. J Occup Health. 2014;56(1):73-83.

9. Busis NA. To revitalize neurology we need to address physician burnout. Neurology. 2015;84(23):2384-5.

10. Miranda-Ackerman RC, Barbosa-Camacho FJ, Sander-Möller MJ, BuenrostroJiménez AD, Mares-País $R$, Cortes-Flores AO, et al. Burnout syndrome prevalence during internship in public and private hospitals: a survey study in Mexico. Med Educ Online. 2019:24(1):1593785.

11. Shanafelt TD, Bradley KA, Wipf JE, Back AL. Burnout and self-reported patient care in an internal medicine residency program. Ann Intern Med. 2002;136(5):358-67.

12. Dyrbye LN, F Stanford M, Anne E, William H, David P, Durning SJ, et al. Relationship between burnout and professional conduct and attitudes among US medical students. JAMA. 2010; 304(11):1173-1180.

13. Dyrbye LN, Burke SE, Hardeman RR, Herrin J, Wittlin NM, Yeazel M. Association of clinical specialty with symptoms of burnout and career choice regret among us resident physicians. JAMA. 2018;320(11):1114-30.

14. Zhang SY, Yan ZQ, Wan XH, Shen Y, Lei GH, Kuang M, et al. Improving graduate medical education in China: leading teaching hospitals engage in self-analysis. J Grad Med Educ. 2018;10(2):125-9.

15. Zhao Y, Zhang S, Li W, Chen L. Pursuing excellence in graduate medical education in China. Lancet. 2016;388(10054):1859-60.

16. Lu Q, Zhu SM, Wang P, Duan SN, Wang JL, Shen H. Analysis of burnout status of clinical postgraduates majoring in obstetrics and gynecology. Chin Higher Med Educ. 2016;(1):98-9 Article in Chinese.

17. Chen $X$. Study of burnout status and influencing factors of clinical graduate students. Health Vocational Educ. 2014;32(20):114-6 (Article in Chinese).

18. Dyrbye LN, West CP, Satele D, Boone S, Tan L, Sloan J, et al. Burnout among U.S. medical students, residents, and early career physicians relative to the general U.S. population. Acad Med. 2014;89(3):443-51.

19. Shanafelt TD, Balch CM, Bechamps GJ. Burnout and career satisfaction among American surgeons. Ann Surg. 2009:250(3):463-71.

20. Zhou XY, Pu JC, Zhong XN, Zhu D, Yin DH, Yang LN, et al. Burnout, psychological morbidity, job stress, and job satisfaction in Chinese neurologists. Neurology. 2017;88(18):1727-35.

21. Yue ZH, Sun LZ, Liu MN, Yu MX, Jiang XY. Investigation and thinking about career satisfaction of medical students. Chin J Modern Drug Application. 2011;5(14):132-4 Article in Chinese.

22. Wang MC, Harrison R, Macintyre R, Travaglia J, Balasooriya C. Burnout in medical students: a systematic review of experiences in Chinese medical schools. BMC Med Educ. 2017:17(1):217.

23. Levin KH, Shanafelt TD, Keran CM, Busis NA, Foster LA, Jrv M, et al. Burnout, career satisfaction, and well-being among US neurology residents and fellows in 2016. Neurology. 2017;89(5):492-501. 
24. Sigsbee B, Bernat JL. Physician burnout: a neurologic crisis. Neurology. 2014;83:2302-6.

25. Dall TM, Storm MV, Chakrabarti R, Drogan O, Keran CM, Donofrio PD, et al. Supply and demand analysis of the current and future US neurology workforce. Neurology. 2014;82(24):2254-5.

26. Pu JC, Zhou XY, Zhu D, Zhong XN, Yang LN, Wang HY, et al. Gender differences in psychological morbidity, burnout, job stress and job satisfaction among Chinese neurologists: a national cross-sectional study. Psychol Health Med. 2017;22(6):680-92.

27. Gorter RC, Storm MK, Brake JHMT, Kersten HW, Eijkman MAJ. Outcome of career expectancies and early professional burnout among newly qualified dentists. Int Dent J. 2007;57(4):279-85.

28. Maslach C, Schaufeli WB, Leiter MP. Job burnout. Annu Rev Psychol. 2001;52(1):397-422.

29. Schaufeli WB, Bakker AB, Hoogduin K, Schaap C, Kladler A. On the clinical validity of the Maslach burnout inventory and the burnout measure. Psychol Health. 2001;16:565-82

30. Ishak WW, Lederer S, Mandili C, Nikravesh R, Seligman L, Vasa M, et al. Burnout during residency training: a literature review. J Grad Med Educ. 2009;1(2):236-42.

31. Busis NA, Shanafelt TD, Keran CM, Levin KH, Schwarz HB, Molano JR, et al. Burnout, career satisfaction, and well-being among US neurologists in 2016. Neurology. 2017;88(8):797-808.

32. Hu NC, Chen JD, Cheng TJ. The associations between long working hours, physical inactivity, and burnout. J Occup Environ Med. 2016;58(5):514-8.

33. van Vendeloo SN, Brand PL, Verheyen CC. Burnout and quality of life among orthopaedic trainees in a modern educational programme: importance of the learning climate. Bone Joint J. 2014;96-B(8):1133-8.

34. Hoffmann H, Dellkuster S, Rosenthal R. Medical students' career expectations and interest in opting for a surgical career. Swiss Med Wkly. 2014:144:w13932

35. Ranta M, Hussain SS, Gardiner Q. Factors that inform the career choice of medical students: implications for otolaryngology. J Laryngol Otol. 2002;116(10):839-41.

36. Dyrbye LN, Thomas MR, Power DV, Durning S, Moutier C, Massie FS Jr, et al. Burnout and serious thoughts of dropping out of medical school: a multi-institutional study. Acad Med. 2010 Jan:85(1):94-102.

37. Neckelmann D, Mykletun A, Dahl AA. Chronic insomnia as a risk factor for developing anxiety and depression. Sleep. 2007;30(7):873-80.

Ready to submit your research? Choose BMC and benefit from:

- fast, convenient online submission

- thorough peer review by experienced researchers in your field

- rapid publication on acceptance

- support for research data, including large and complex data types

- gold Open Access which fosters wider collaboration and increased citations

- maximum visibility for your research: over $100 \mathrm{M}$ website views per year

At BMC, research is always in progress.

Learn more biomedcentral.com/submissions 